\title{
Factors associated with osteoporosis among a sample of Jordanian women referred for investigation for osteoporosis
}

\author{
M.A. El-Heis, ${ }^{1}$ E.A. Al-Kamil, ${ }^{2}$ K.A. Kheirallah, ${ }^{3}$ T.N Al-Shatnawi, $^{4}$ M. Gharaibia ${ }^{7}$ and A. Al-Mnayyis ${ }^{1}$
}

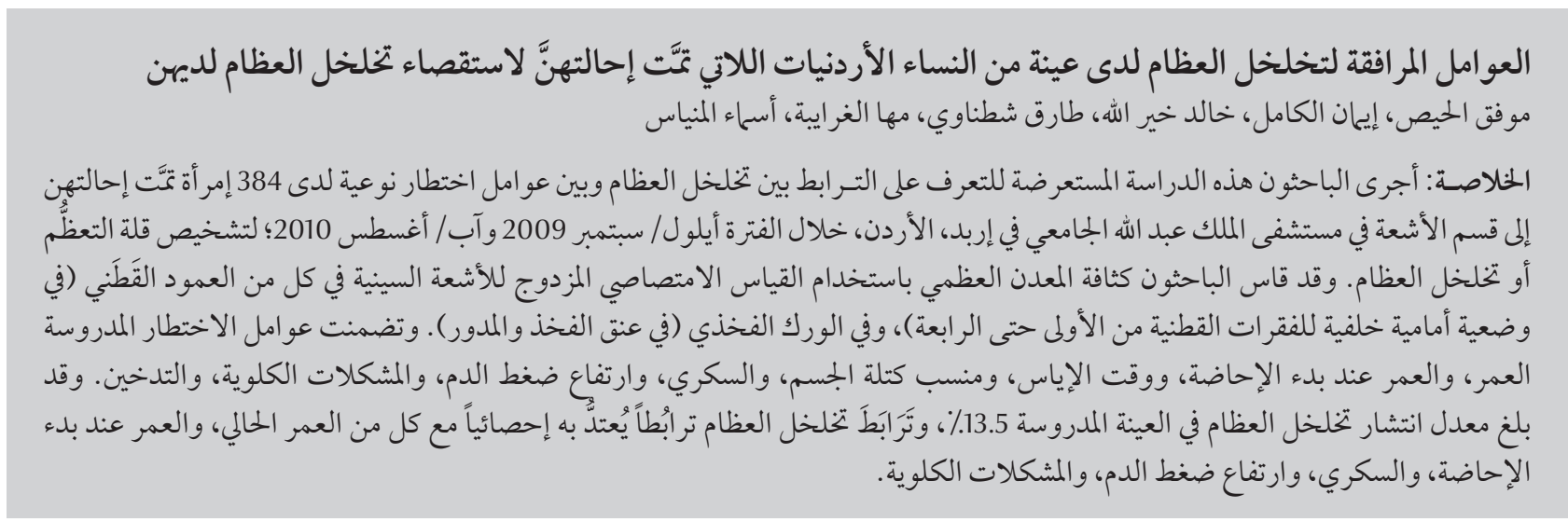

ABSTRACT This cross-sectional study was carried out to examine the association between osteoporosis and specific risk factors among 384 women referred to the Radiology Department at King Abdullah University Hospital, Irbid, Jordan during the period September 2009-August 2010 for diagnosis of osteopenia or osteoporosis. Bone mineral density measurements were carried out using dual energy X-ray absorptiometry at both the lumbar spine [AP: L1-L4] and femoral hip (neck, trochanter). Studied risk factors included age, age at menarche, menopause, body mass index, diabetes mellitus, hypertension, renal problems and smoking. The prevalence of osteoporosis among the studied sample was 13.5\%. Osteoporosis was significantly associated with current age, age at menarche, diabetes mellitus, hypertension, and renal problems.

Facteurs associés à l'ostéoporose dans un échantillon de femmes jordaniennes orientées pour un dépistage de l'ostéoporose

RÉSUMÉ La présente étude transversale a été menée pour étudier l'association entre l'ostéoporose et des facteurs de risque spécifiques chez 384 femmes orientées vers le service de radiologie de l'hôpital universitaire du Roi Abdallah à Irbid (Jordanie), entre septembre 2009 et août 2010, pour un diagnostic d'ostéopénie ou d'ostéoporose. Des mesures de la densité minérale osseuse ont été prises à l'aide d'une absorptiométrie biénergétique à rayons $X$, au niveau du rachis lombaire (L1-L4) et de l'articulation fémorale (col, trochanter). Les facteurs de risque étudiés étaient l'âge au moment de l'étude, l'âge des premières règles et à la ménopause, l'indice de masse corporelle, la présence d'un diabète, d'une hypertension ou de problèmes rénaux ainsi que la consommation de tabac. La prévalence de l'ostéoporose au sein de l'échantillon étudié était de 13,5\%. L'ostéoporose était significativement associée à l'âge au moment de l'étude, l'âge des premières règles, la présence d'un diabète, d'une hypertension et de problèmes rénaux.

${ }^{7}$ Radiology Department; ${ }^{3}$ Community Medicine Department; ${ }^{4}$ Faculty of Nursing, King Abdullah University Hospital, Faculty of Medicine, Jordan University of Science and Technology, Irbid, Jordan (Correspondence to M.A. El-Heis: elheis@hotmail.com).

${ }^{2}$ Department of Basic Medical Sciences \& Community Medicine, Faculty of Medicine, Hashemite University, Zarqa, Jordan.

Received: 31/10/11; accepted: 12/12/11 


\section{Introduction}

Osteoporosis is prevalent in aged adults, mostly in postmenopausal women. Diagnosis depends mainly on the quantitative assessment of bone mineral density, which is considered the most important determinant of bone strength. The clinical significance of osteoporosis is from the potential for causing fractures [1]. There are several sites of potential occurrence for osteoporotic fracture including: the spine, hip, distal forearm and proximal humerus [2].

In a study done in the North America it was estimated that 1 in 3 women and 1 in 12 men over the age of 50 worldwide have osteoporosis [3]. Osteoporosis affected about 10 million women and men in the United States in $2005[4,5]$. In Sweden, osteoporosis was estimated to affect $6.3 \%$ of men and $21.2 \%$ of women aged $50-80$ years $[6]$.

A number of studies have been done in the countries of the Middle East [7-11]. The prevalence in Lebanon is estimated to be $31 \%$ among women according to WHO criteria. In Kuwait, the prevalence of osteoporosis in $\mathrm{Ku}$ waiti women was about $18 \%$. In Jordan $13 \%$ of the females above 40 years of age were osteoporotic. In Saudi Arabia, the prevalence of osteoporosis among the Saudi population was estimated in the range $35 \%-48 \%$. In another study, the prevalence of osteoporosis among Saudi females over 31 years was 0\%$7 \%$, whereas it was about $28 \%$ among women over 50 years [12].

The risk factors associated with osteoporosis may be modifiable or non-modifiable [13]. Non-modifiable risk factors include age and sex: estrogen deficiency following menopause or oophorectomy is correlated with a rapid reduction in bone mineral density. Ethnicity is also recognized as a nonmodifiable risk factor and European or Asian ancestry predisposes for osteoporosis. Genetics is also a predisposing factor: those with a family history of osteoporosis are more likely to have increased risk [14].

Diabetes mellitus (DM) is associated with increased incidence of osteoporosis fractures via visual impairments resulting from diabetic retinopathy and cataract [15]. Adult women with type $1 \mathrm{DM}$ also have relatively decreased bone mass, increased fracture risk, and delayed fracture healing compared with healthy women without DM. In addition, researchers have shown that the biomechanical integrity of diabetic bone may be impaired [16]. However, this is not so for patients with type $2 \mathrm{DM}$; in fact, they may be relatively protected from osteoporosis.

Menopause is a major risk factor for osteoporosis. The incidence of fractures increases by about $40 \%$ with menopause in developing countries [8]. The relationship between osteoporosis and hypertension can be understood through menopause: the underlying mechanism is through hormonal changes as part of the aging process and the accompanying reduction in estrogen and progesterone [17]. Age itself is also a risk factor since it is associated with low bone mineral density; the risk for osteoporosis is doubled among elderly women [18].

Increased age at menarche affects the incidence of osteoporosis. Menarche after age 14 years is associated with increased incidence of osteoporosis. This risk factor is most likely associated with estrogen deprivation [19].

Body mass index (BMI) is also a risk factor, with obesity being a protective factor. A lower incidence of fractures has been reported in obese women [20].

Renal problems are also regarded as a risk factor through the metabolism of vitamin $\mathrm{D}$ and parathyroid hormone. When metabolic disturbances end with decreased calcium level, bone resorption is likely to occur and this can lead to osteoporosis [21].
Other risk factors, the modifiable risk factors, depend on lifestyle, and can be avoided. These include: alcohol, vitamin $\mathrm{D}$ deficiency, tobacco smoking, malnutrition, a high protein diet, excess physical activity, heavy metals and soft drinks [22-24].

\section{Objectives}

This study was carried out to examine the risk factors associated with osteoporosis among Jordanian women referred to the Radiology Department at King Abdullah University Hospital. The risk factors studied included, age, age at menarche, menopause, DM, renal problems, hypertension, BMI and smoking.

\section{Methods}

This cross-sectional study was conducted at King Abdullah University Hospital, Irbid, Jordan. The study involved all 392 female patients referred to the Department of Radiology from other specialty departments during the period September 2009 to August 2010. The sample comprised 51 inpatients admitted to the Orthopaedics wards for surgical treatment for fractures at different sites. The remaining 333 patients were referred from Medicine, Orthopaedics, Endocrinology and Urology outpatients departments for the diagnosis of osteopenia or osteoporosis. Eight patients were excluded from the study: 3 were severely ill with multiple fractures and 5 refused to be involved in the study after full explanation of the aims. The finals sample included 384 women, a response rate of $97.9 \%$.

All participants were informed about the research study and gave informed approval. The study was approved by the ethical committee of Jordan Univere sity of Science and Technology.

A special question form was designed by the researchers for the purpose of the study after reviewing 
previous studies. This was evaluated by the scientific committee of the university. The questionnaire was adminise tered and completed by the researchers by interviewing the patients. The main information gathered included sociodemographic characteristics, weight, height, and age at menarche, menopause, and reported illnesses such as $\mathrm{DM}$, hypertension, renal problems and smoking status.

All patients who had clinical, radiological or serological findings of osteoarthritis or rheumatoid arthritis were excluded. Patients on steroid treatment were also excluded.

\section{Measurement of bone mineral density}

Bone mineral density measurements at both the lumbar spine [AP: L1-L4] and femoral hip (neck, trochanter) were carried out by using dual-energy X-ray absorptiometry (DXA), which is considered the gold standard for the diagnosis of osteoporosis. We used the following diagnostic guidelines [25]: normal: $T$-score $\geq-1.0$; low bone mass (osteopenia): $\mathrm{T}$-score between -1.0 and -2.5 ; osteoporosis: $\mathrm{T}$-score $\leq-2.5$.

We used the Word Health Organization definition of BMI [26]: normal: BMI $18.5-<25 \mathrm{~kg} / \mathrm{m}^{2}$; overweight: BMI $25-30 \mathrm{~kg} / \mathrm{m}^{2}$; obese: $\mathrm{BMI}>30 \mathrm{~kg} / \mathrm{m}^{2}$.

\section{Data analysis}

Data analysis was carried out using SPSS, version 17 . The chi-squared test was used as a test of significance $(P<0.05)$ for the unadjusted effect. Backward stepwise conditional multivariate regression analysis was used to investigate and quantify the adjusted effect of each of the independent variables on the disease status using adjusted odds ratio (OR) and $95 \%$ confidence interval (CI).

\section{Results}

Table 1 shows the distribution of the study population according to

Table 1 Distribution of Jordanian women patients $(n=384)$ referred for radiology, according to dependent and independent variables

\begin{tabular}{|c|c|c|}
\hline Variable & No. & $\%$ \\
\hline \multicolumn{3}{|c|}{ Current age (years) } \\
\hline$<50$ & 108 & 28.1 \\
\hline $50-60$ & 119 & 31.0 \\
\hline$>60$ & 157 & 40.9 \\
\hline \multicolumn{3}{|c|}{ Age at menarche (years) } \\
\hline$<13$ & 312 & 81.3 \\
\hline$\geq 13$ & 68 & 17.7 \\
\hline Missing data & 4 & 1.0 \\
\hline \multicolumn{3}{|l|}{ Body mass index } \\
\hline Normal & 49 & 12.8 \\
\hline Overweight & 121 & 31.5 \\
\hline Obesity & 214 & 55.7 \\
\hline \multicolumn{3}{|l|}{ Diagnosis } \\
\hline Normal & 184 & 47.9 \\
\hline Osteopenia & 148 & 38.5 \\
\hline Osteoporosis & 52 & 13.5 \\
\hline \multicolumn{3}{|l|}{ Menopause } \\
\hline Yes & 292 & 76.0 \\
\hline No & 90 & 23.6 \\
\hline Missing data & 2 & 0.4 \\
\hline \multicolumn{3}{|c|}{ Diabetes mellitus } \\
\hline Yes & 50 & 13.0 \\
\hline No & 334 & 87.0 \\
\hline \multicolumn{3}{|l|}{ Hypertension } \\
\hline Yes & 69 & 18.0 \\
\hline No & 315 & 82.0 \\
\hline \multicolumn{3}{|l|}{ Renal problems } \\
\hline Yes & 18 & 4.7 \\
\hline No & 366 & 95.3 \\
\hline \multicolumn{3}{|l|}{ Smoking } \\
\hline Yes & 17 & 4.4 \\
\hline No & 367 & 95.6 \\
\hline
\end{tabular}

descriptive variables. Just over $80 \%$ of the women reported age at menarche as $<13$ years. Just $13.5 \%$ of the women were diagnosed as osteoporotic, with $38.5 \%$ osteopenic. DM was reported by $13.0 \%, 18.0 \%$ had hypertension, and $4.7 \%$ had renal problems.

Table 2 shows the distribution of the study population according to bone mineral density and clinical variables. It shows that $25.5 \%$ of the women aged $>60$ years had osteoporosis compared to only $7.4 \%$ of those aged $<50$ years and the difference was statistically significant $(P<0.001)$.

Age at menarche was statistically significantly associated with osteoporosis: $15.7 \%$ of osteoporotic women reported age at menarche at $<13$ years compared to $4.4 \%$ at age $\geq 13$ years $(P<0.001)($ Table 2$)$. The proportion of menopausal women with osteopenia (46.6\%) and osteoporosis (13.0\%) was statistically significantly greater than for nonmenopausal women $(13.3 \%$ and 


\begin{tabular}{|c|c|c|c|c|c|c|c|c|c|}
\hline \multirow[t]{3}{*}{ Variable } & \multicolumn{6}{|c|}{ Bone mineral density } & \multicolumn{2}{|c|}{ Total } & \multirow[t]{3}{*}{$P$-value } \\
\hline & \multicolumn{2}{|c|}{ Normal } & \multicolumn{2}{|c|}{ Osteopenia } & \multicolumn{2}{|c|}{ Osteoporosis } & \multirow[b]{2}{*}{ No. } & \multirow[b]{2}{*}{$\%$} & \\
\hline & No. & $\%$ & No. & $\%$ & No. & $\%$ & & & \\
\hline \multicolumn{10}{|l|}{ Age (years) } \\
\hline$<50$ & 71 & 65.7 & 29 & 26.8 & 8 & 7.4 & 108 & 28.1 & \multirow{4}{*}{$<0.001$} \\
\hline $50-60$ & 68 & 57.1 & 47 & 39.5 & 4 & 3.4 & 119 & 31.0 & \\
\hline$>60$ & 45 & 28.7 & 72 & 45.8 & 40 & 25.5 & 157 & 40.9 & \\
\hline Total & 184 & 47.9 & 148 & 38.5 & 52 & 13.5 & 384 & 100.0 & \\
\hline \multicolumn{10}{|c|}{ Age at menarche (years) } \\
\hline$<13$ & 118 & 37.8 & 145 & 46.5 & 49 & 15.7 & 312 & 82.1 & \multirow{3}{*}{$<0.001$} \\
\hline$\geq 13$ & 62 & 91.2 & 3 & 4.4 & 3 & 4.4 & 68 & 17.9 & \\
\hline Total & 180 & 47.4 & 148 & 38.9 & 52 & 13.7 & 380 & 100.0 & \\
\hline \multicolumn{10}{|c|}{ Body mass index } \\
\hline Normal & 19 & 38.8 & 20 & 40.8 & 10 & 20.0 & 49 & 12.8 & \multirow{4}{*}{$>0.05$} \\
\hline Overweight & 64 & 52.9 & 40 & 33.0 & 17 & 14.0 & 121 & 31.5 & \\
\hline Obese & 101 & 47.2 & 88 & 41.1 & 25 & 11.7 & 214 & 55.7 & \\
\hline Total & 184 & 47.9 & 148 & 38.5 & 52 & 13.5 & 384 & 100.0 & \\
\hline \multicolumn{10}{|l|}{ Menopause } \\
\hline Yes & 118 & 40.4 & 136 & 46.6 & 38 & 13.0 & 292 & 76.4 & \multirow{3}{*}{$<0.001$} \\
\hline $\mathrm{No}+$ & 64 & 71.1 & 12 & 13.3 & 14 & 10.5 & 90 & 23.6 & \\
\hline Total & 182 & 47.6 & 148 & 38.7 & 52 & 13.6 & 382 & 100.0 & \\
\hline \multicolumn{10}{|c|}{ Diabetes mellitus } \\
\hline Yes & 24 & 48.0 & 12 & 24.0 & 14 & 28.0 & 50 & 13.0 & \multirow{3}{*}{$<0.01$} \\
\hline No & 160 & 48.0 & 136 & 40.7 & 38 & 11.3 & 334 & 87.0 & \\
\hline Total & 184 & 48.0 & 148 & 38.5 & 52 & 13.5 & 384 & 100.0 & \\
\hline \multicolumn{9}{|l|}{ Hypertension } & \multirow[t]{4}{*}{$<0.001$} \\
\hline Yes & 43 & 62.3 & 12 & 17.4 & 14 & 20.3 & 69 & 18.0 & \\
\hline No & 141 & 44.8 & 136 & 43.2 & 38 & 12.0 & 315 & 82.0 & \\
\hline Total & 184 & 48.0 & 148 & 38.5 & 52 & 13.5 & 384 & 100.0 & \\
\hline \multicolumn{10}{|l|}{ Renal problems } \\
\hline Yes & 5 & 27.8 & 6 & 33.3 & 7 & 38.9 & 18 & 4.7 & \multirow{3}{*}{$<0.01$} \\
\hline No & 179 & 49.0 & 142 & 38.8 & 45 & 12.2 & 366 & 95.3 & \\
\hline Total & 184 & 48.0 & 148 & 38.5 & 52 & 13.5 & 384 & 100.0 & \\
\hline \multicolumn{10}{|l|}{ Smoking } \\
\hline Yes & 11 & 64.7 & 3 & 17.6 & 3 & 17.6 & 17 & 4.4 & \multirow{3}{*}{$>0.05$} \\
\hline No & 173 & 47.1 & 145 & 39.5 & 49 & 13.4 & 367 & 95.6 & \\
\hline Total & 184 & 48.0 & 148 & 38.5 & 52 & 13.5 & 384 & 100.0 & \\
\hline
\end{tabular}

$10.5 \%$ respectively) and the difference was statistically significant $(P<$ 0.001 ).

Also, $28.0 \%$ of women with DM had osteoporosis compared with $11.3 \%$ among women with no DM $(P<0.01)$ (Table 2).

Having hypertension $(P<0.001)$ and renal problems $(P<0.01)$ also had statistically significant relations with osteoporosis (Table 2).
Logistic regression of factors associated with osteoporosis

Logistic regression showed that age, $\mathrm{DM}$, and age at menarche were the most significant predictors of osteoporosis (Table 3 ). Women who were $<50$ years old were only 0.36 times as likely to have osteoporosis compared with those who were $>60$ years old. This relationship was statistically significant (OR $=0.36$; 95\% CI: 0.15-0.83).
Participants who reported having DM were 2.56 times more likely to have osteoporosis compared with those who did not report having DM (Table 3). This relationship was statistically significant (95\% CI: 1.19-5.50). Women who reported menarche at age $\leq 13$ years were 2.86 more likely to have osteoporosis. However this relationship was not statistically significant $(95 \% \mathrm{CI}$ : 0.81-10.11). 


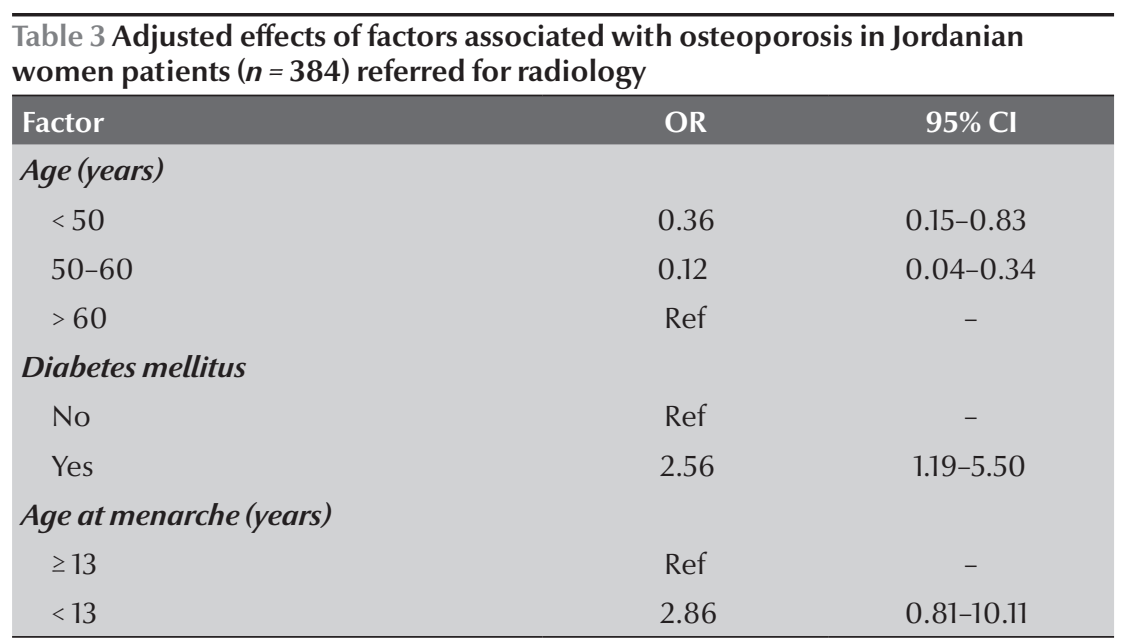

$O R=$ odds ratio $; \mathrm{Cl}=$ confidence interval.

Ref $=$ reference category.

\section{Discussion}

Our data showed that the prevalence of osteoporosis among Jordanian women who had been referred for assessment of bone density by their physicians was $13.5 \%$, which is lower than that reported for some other populations. A higher prevalence of osteoporosis was reported for postmenopausal Caucasian women (30\%) [27], (21.2\%) in Swedish women aged 50-80 [6]. It is also lower than that reported for women in some Arab countries $[11,12]$ : in Lebanon, the prevalence of osteoporosis in women was reported to be $31 \%$, in Kuwaiti women $18 \%$, in Saudi Arabia it was $28 \%$ among women aged over 50 years and in Jordan it was estimated to be $13 \%$ of females over 40 years of age.

The data obtained from the present study showed no significant relationship between BMI and osteoporosis although other researchers have found low BMI to be significantly related with osteoporosis [28]. This could be because some of the measurements were taken from the medical records because the patients were not available and we could not ascertain their accuracy of these records.

Our findings demonstrated a significant correlation between age and osteoporosis. As the age increases, osteoporotic cases increase, especially after 60 years, this is consistent with other studies where osteoporosis is prevalent in women after 60 . Several reasons were reported age as a risk factor due to estrogen deficiency after menopause $[6,29,30]$.

Regarding the relation between age at menarche and osteoporosis, some researchers have found that osteoporosis was more prevalent among women having their menarche after the age of 13 years [17], but this is not comparable with our findings. This may be related to the fact that some women may forgot or do not accurately recall the exact date of their menarche [31,32].

Menopause is an important predictor of osteoporosis associated as it leads to bone weakness. The findings of this study are comparable with those of other reported studies [14,30,33].

We found that significantly more women with DM had osteoporosis than women with no DM; this is comparable to the findings of other studies in which DM correlated significantly with osteoporosis $[15,34]$.

The basic mechanism of association between hypertension and osteoporosis has not been clarified yet. The latest research has shown that rennin-angiotensin system plays a main role in blood pressure control and has an influence on bone density [35]. High blood pressure is associated with calcium metabolism disorder, which affects increased secretion of calcium through urine [35]. Our findings showed that significantly more hypertensive women had osteoporosis than non-hypertensive women, which is comparable to other research in which a significant correlation between hypertension and osteoporosis, thought to be through a link between cardiovascular diseases and osteoporosis, was demonstrated [36].

Our results showed that renal problems were significantly associated with osteoporosis, which is comparable to other research which reported an association thought to be related to increased calcium excretion [37]. Bone disease may occur early in the course of kidney disease, and worsens as the decline in kidney function progresses, and bone density tends to be worse in cortical sites. Kidney patients also may have poor quality bone, so they can suffer fractures even without severe loss of bone mass [36,38].

Smoking was not shown to be associated significantly with osteoporosis in our study; this is contrary to the findings of some other studies in which smoking was considered a significant factor [17-19]. We think that the reason may be under-reporting of smoking among our participants because all of them were females living in a conservative community.

On consideration of the results of this study, we recommend the evaluation or measuring of bone mineral density for menopausal women, and women with DM, hypertension and renal problems for early detection of osteopenia or osteoporosis.

The main limitation of this study is that it included women with health problems. We recommended that any further national study should involve women in the community.

Competing interests: None declared. 


\section{References}

1. Kanis JA et al.; European Society for Clinical and Economic Aspects of Osteoporosis and Osteoarthritis (ESCEO). European guidance for the diagnosis and management of osteoporosis in postmenopausal women. Osteoporosis International, 2008, 19:399-428.

2. Kanis JA et al. Long-term risk of osteoporotic fracture in Malmö. Osteoporosis International, 2000, 11:669-674.

3. America's bone health: the state of osteoporosis and low bone mass in our nation. Washington DC, National Osteoporosis Foundation, 2002.

4. Nayak S, Roberts MS, Greenspan SL. Factors associated with diagnosis and treatment of osteoporosis in older adults. Osteoporosis International, 2009, 20:1963-1967.

5. Burge R et al. Incidence and economic burden of osteoporosis-related fractures in the United States, 2005-2025. Journal of Bone and Mineral Research, 2007, 22:465-475.

6. Kanis JA et al. Risk of hip fracture according to the World Health Organization criteria for osteopenia and osteoporosis. Bone, 2000, 27:585-590.

7. Ardawi MSM et al. Bone mineral density of the spine and femur in healthy Saudis. Osteoporosis International, 2005, 16:43-55.

8. Sadat-Ali $\mathrm{M}$ et al. Bone mineral density among postmenopaut sal Saudi women. Saudi Medical Journal, 2004, 25:1623-1625.

9. Sadat-Ali M, Al-Habdan I, Marwah S. Bone mineral density measurements of distal radius in Saudi Arabian females. Annals of Saudi Medicine, 1996, 16:414-416.

10. El-Desouki MI. Osteoporosis in postmenopausal Saudi women using dual x-ray bone densitometry. Saudi Medical Journal, 2003, 24:953-956.

11. The Middle East \& Africa regional audit. Epidemiology, costs \& burden of osteoporosis in 2011. Nyon, Switzerland, International Osteoporosis Foundation, 2011 (http://www.iofbonehealth. org/middle-east-africa-audit, accessed 15 March 2013).

12. Sadat-AM et al. An epidemiological analysis of the incidence of osteoporosis and osteoporosis-related fractures among the Saudi Arabian population. Annals of Saudi Medicine, 2012, 32(6):637-641.

13. Melton LJ 3rd. Epidemiology worldwide. Endocrinology and Metabolism Clinics of North America, 2003, 32:1-13.

14. Raisz LG. Pathogenesis of osteoporosis: concepts, conflicts, and prospects. Journal of Clinical Investigation, 2005, 115:33183325.

15. Wongdee K, Charoenphandhu N. Osteoporosis in diabetes mellitus: Possible cellular and molecular mechanisms. World Journal of Diabetes, 2011, 2:41-48.

16. 6 Reddy GK et al. The biomechanical integrity of bone in experimental diabetes. Diabetes Research and Clinical Practice, 2001, 54:1-8.

17. Matziolis D et al. Treated hypertension has no influence on the efficacy of alendronate in the therapy of postmenopausal osteoporosis: a non-randomized, non-blind, controlled prospective study. Open Orthopaedics Journal, 2011, 5:27-31.

18. Kanis JA et al. Ten year probabilities of osteoporotic fractures according to BMD and diagnostic thresholds. Osteoporosis International, 2001, 12:989-995.

19. Keramat $\mathrm{A}$ et al. The assessment of osteoporosis risk factors in Iranian women compared with Indian women. BMC Musculoskeletal Disorders, 2008, 9:28.
20. Mahan LK, Escott-Stump S, eds. Krause's food, nutrition and diet therapy, 7th edition. Philadelphia, WB Saunders, 2000:618.

21. Eisman JA. Genetics of osteoporosis. Endocrine Reviews, 1999, 20:788-804.

22. Poole KE, Compston JE. Osteoporosis and its management. BMJ (Clinical Research Ed.), 2006, 333:1251-1256.

23. Berg KM et al. Association between alcohol consumption and both osteoporotic fracture and bone density. American Journal of Medicine, 2008, 121:406-418.

24. Nieves JW. Osteoporosis: the role of micronutrients. American Journal of Clinical Nutrition, 2005, 81:1232S-1239S.

25. Prevention and management of osteoporosis: report of a WHO scientific group. Geneva, World Health Organization, 2003 (WHO Technical Report Series 921) (http://whqlibdoc.who. int/trs/WHO_TRS_921.pdf, accessed 14 February 2013).

26. Jingfu $M$ et al. [Relationship between weight, height, body mass index and BMD in postmenopausal women]. Chinese journal of osteoporosis, 1998, 04.

27. Genant HK et al. Interim report and recommendations of the World Health Organization Task Force for Osteoporosis. Osteoporosis International, 1999, 10(4):259-264.

28. De Laet $\mathrm{C}$ et al. Body mass index as a predictor of fracture risk: a meta-analysis. Osteoporosis International, 2005, 16:1330-1338.

29. Li S et al. The correlation of osteoporosis to clinical features: a study of 4382 female cases of a hospital cohort with musculoskeletal symptoms in southwest China. BMC Musculoskeletal Disorders, 2010, 11:183-192.

30. McNamara LM. Perspective on post-menopausal osteoporosis: establishing an interdisciplinary understanding of the sequence of events from the molecular level to whole bone fractures. Journal of the Royal Society, Interface, 2010, 7:353-372.

31. Scheiber LB 2nd, Torregrosa L. Evaluation and treatment of postmenopausal osteoporosis. Seminars in Arthritis and Rheumatism, 1998, 27:245-261.

32. Leslie M, St Pierre RW, Richard W. Osteoporosis: implications for risk reduction in the college setting. Journal of American College Health, 1999, 48:67-71.

33. Li HL, Zhu HM. [Relationship between the age of menarche, menopause and other factors and postmenopause osteoporosis.] Zhonghua Fu Chan Ke Za Zhi, 2005, 40(12):796-798 [in Chinese].

34. Zethraeus $\mathrm{N}$ et al. The cost effectiveness of the treatment of osteoporosis, hypertension and hyperlipidaemia in Sweden. Osteoporosis International, 2007, 18:9-23.

35. Popović MR, Tasić I. Association between hypertension and osteoporosis in postmenopausal women. Acta Medica Medianae, 2009, 48:8-14.

36. Stehman-Breen C. Osteoporosis and chronic kidney disease. Seminars in Nephrology, 2004, 24:78-81.

37. Genant HK et al. Noninvasive assessment of bone mineral and structure: state of the art.Journal of Bone and Mineral Research, 1996, 11:707-730.

38. Cunningham J et al.; Osteoporosis Work Group. Osteoporosis in chronic kidney disease. American Journal of Kidney Diseases, 2004, 43:566-571. 